\title{
The Influence of Microstructure on Corrosion Resistance of Mg-3Al-1Zn-15Li (LAZ1531) Alloy
}

\author{
Anna Dobkowska, Bogusława Adamczyk-Cieślak, Aleksandra Towarek, Piotr Maj, Ewa Ura-Bińczyk, Mojtaba Momeni, Dariusz Kuc, \\ Eugeniusz Hadasik, and Jarosław Mizera
}

(Submitted November 1, 2019; in revised form January 13, 2020; published online April 13, 2020)

\begin{abstract}
In this study, the microstructure and corrosion resistance of the as-extruded and as-extruded with subsequent heat treatment Mg-3Al-1Zn-15Li (LAZ1531) alloys have been investigated. The alloys' microstructures consisted of $\alpha(\mathrm{Mg}), \beta(\mathrm{Li}), \Theta-\mathrm{MgLi}_{2} \mathrm{Al}$ and $\mathrm{Mg}_{17} \mathrm{Al}_{12}$. As a result of annealing, the $\beta(\mathrm{Li})$ to $\alpha(\mathrm{Mg})$ transformation occurred, and the recrystallization supported the reformation of the $\operatorname{Mg}_{17} \mathbf{A l}_{12}$. The electrochemical tests showed that the increased amount of $\alpha(\mathrm{Mg})$ and higher amount of $\mathrm{Mg}_{17} \mathrm{Al}_{12}$ in the heattreated alloy favored reactions and determined it as having better corrosion resistance in $3.5 \mathrm{wt} \% \mathrm{NaCl}$.
\end{abstract}

Keywords corrosion and wear, electron microscopy, heat treatment, lithium, magnesium, x-ray

\section{Introduction}

Increasing pressures associated with environmental factors such as carbon oxides in the atmosphere and increasing fuel costs are driving many industrial branches to look for advanced lightweight materials with the lowest possible densities such as magnesium or aluminum alloys. One way to decrease the weight of the materials is the use of alloying elements such as $\mathrm{Li}$, which has a density of $0.534 \mathrm{~g} \mathrm{~cm}^{-3}(\operatorname{Ref} 1,2)$. Li can reduce magnesium alloys densities from $1.75 \mathrm{~g} \mathrm{~cm}^{-3}$ for the AZ31 alloy, while Mg alloys with more than 11 wt.\% of Li can have densities as low as $1.33 \mathrm{~g} \mathrm{~cm}^{-3}$ (Ref 3,4). According to the equilibrium diagram for $\mathrm{Mg}-\mathrm{Li}$, additions over $11 \mathrm{wt} . \%$ of $\mathrm{Li}$ also change the hexagonal close package (HCP) lattice of $\mathrm{Mg}$ into a body-centered cubic (BCC) one, which plays a significant role in plastic deformation as it facilitates secondary slip systems (Ref 5-10). Mg alloys with more than $11 \mathrm{wt} . \%$ of $\mathrm{Li}$ are also characterized by poor strength and better plasticity compared to $\mathrm{Mg}-\mathrm{Li}$ alloys with less than $11 \mathrm{wt} \%$ of $\mathrm{Li}$ (Ref

\footnotetext{
Anna Dobkowska, Faculty of Materials Science and Engineering, Warsaw University of Technology, Woloska, 141, 02-507 Warsaw, Poland; and Chemistry Department, The University of Western Ontario, 1151 Richmond St, London, ON N6A 5B7, Canada; Bogusława Adamczyk-Cieślak, Aleksandra Towarek, Piotr Maj, Ewa Ura-Bińczyk, and Jarosław Mizera, Faculty of Materials Science and Engineering, Warsaw University of Technology, Woloska, 141, 02-507 Warsaw, Poland; Mojtaba Momeni, Chemistry Department, The University of Western Ontario, 1151 Richmond St, London, ON N6A 5B7, Canada; and Dariusz Kuc and Eugeniusz Hadasik, Institute of Materials Engineering, Silesian University of Technology, Krasinskiego 8, 40-019 Katowice, Poland. Contact e-mails: anna.dobkowska@pw.edu.pl, boguslawa. cieslak@pw.edu.pl, aleksandra.towarek.dokt@pw.edu.pl, piotr. maj@pw.edu.pl, ewa.binczyk@pw.edu.pl, mmomeni3@uwo.ca, dariusz.kuc@polsl.pl, eugeniusz.hadasik@polsl.pl, and jaroslaw. mizera@pw.edu.pl.
}

11). $\mathrm{Zn}$ and $\mathrm{Al}$ have some solubility in $\mathrm{Mg}$-Li alloys, their addition to its chemical composition could increase its strength (Ref 12-14). Al also provides strengthening by the mean of grain size refining, solid solution hardening, and compounds' reinforcements (Ref 15, 16).

Actual studies concerning $\beta$ phase $\mathrm{Mg}-\mathrm{Li}$ alloys focus mostly on microstructural features that can improve the mechanical properties of the mentioned materials (Ref 17-20). It has been observed that depending on the alloying elements and type of subsequent deformation, the $\mathrm{Al}_{12} \mathrm{Mg}_{17}, \Theta-$ $\mathrm{MgLi}_{2} \mathrm{Al}$, AlLi and other compounds of precipitates which are enriched in $\mathrm{Al}$ can be present in $\beta$ phase $\mathrm{Mg}$-Li alloys (Ref 21-23). Their role depends on the multiple factors such as type of deformation or treatment. The presence of $\theta-\mathrm{MgLi}_{2} \mathrm{Al}$ phase in the Mg-9Li-6Al was detected by Qu et al. (Ref 24). Authors proved that the hardness of aging state of LA96 was lower that of solution state, and this was associated with the transformation of $\theta-\mathrm{MgLi}_{2} \mathrm{Al}$ to $\mathrm{AlLi}$ phase. It is worth mentioning that solid solution parameters and their influence on the microstructure evaluation of Mg-9Li-6Al and Mg-9Li-6Al-2Y were also investigated (Ref 23). It was stated that under the conditions of $340{ }^{\circ} \mathrm{C}$ for $0.5 \mathrm{~h}, \theta-\mathrm{MgLi}_{2} \mathrm{Al}$ was dissolved into $\beta(\mathrm{Li})$, and AlLi precipitated from $\alpha(\mathrm{Mg})$. However, the ternary $\theta-\mathrm{MgLi}_{2} \mathrm{Al}$ was also detected in the alloys with lower $\mathrm{Al}$ content, f.e. Liu et al. (Ref 25) found the $\theta-\mathrm{MgLi}_{2} \mathrm{Al}$ in the LA141.

The most common and problematic issue, besides unsatisfactory mechanical properties of the $\beta$ phase $\mathrm{Mg}$-Li alloys, is their weak corrosion resistance (Ref 26-28). In the present study, the design of an Mg-3Al-1Zn-15Li is described with a focus on the influence of microstructural properties on the mentioned $\mathrm{Mg}-\mathrm{Li}$ alloys after conventional extrusion, and after conventional extrusion with subsequent annealing in respect to their corrosion resistance.

\section{Materials}

The AZ31 alloy (3\% Al wt, 1\% Zn wt.) was melted in a Balzers vacuum furnace and 15 wt.\% of high-purity $\mathrm{Li}$ was added into the composition. As a result of melting, the circular rods with a diameter of $\Phi 40 \mathrm{~mm}$ were obtained and extruded up to $\Phi 20 \mathrm{~mm}$. The extrusion was carried out at a $200{ }^{\circ} \mathrm{C}$ with 
a strain rate of $0.5 \mathrm{~s}^{-1}$. A second set of materials was also hot extruded to $\Phi 20 \mathrm{~mm}$, and then heat treated under isothermal conditions at $200{ }^{\circ} \mathrm{C}$ for $1 \mathrm{~h}$. The conditions of the extrusion (temperature and strain rate) and subsequent heat treatment (temperature and duration) were chosen to prevent unfavorable grain growth in the produced alloys (Ref 29, 30).

\section{Methodology}

The Li concentration was measured utilizing atomic absorption spectrometry (AAS) using a GBC Plus machine. The optical images were done after chemical etching in a $4 \mathrm{wt} . \%$ nital reagent applying Zeiss AxioScope A1 microscope. The phase composition of the analyzed materials was determined using the Bruker D8 Advance diffractometer. X-ray diffraction (XRD) investigations were performed at $40 \mathrm{kV}$ and $40 \mathrm{~mA}$ with $\mathrm{Cu} \mathrm{K} \alpha$ radiation with step scanning $2 \theta$ from $20^{\circ}$ to $100^{\circ}$ and a step size of $0.02^{\circ}$. A count time of $10 \mathrm{~s}$ per step was used. By comparing the integrated intensities of the diffraction peaks from each of known phases, the semi-quantitative analysis of the relative composition of the microstructure constituents was done. To describe the characteristic temperatures of exothermic or endothermic reactions occurring in materials, differential scanning calorimetry measurement (DSC) was performed using Pekin Elmer DSC8000. The sample of $10.2 \mathrm{mg}$ was heated up to $450{ }^{\circ} \mathrm{C}$, and data were collected at a heating rate of $20 \mathrm{~K} /$ min. The high-purity Ar was used as purge gas.

The corrosion resistance of the alloys was evaluated in a 3.5 wt. $\% \mathrm{NaCl}$ solution at ambient temperature using FAS1 Gamry potentiostat. A traditional three electrodes setup was used with platinum wire as a counter electrode, an $\mathrm{Ag} / \mathrm{AgCl}$ as a reference electrode and a sample as a working electrode. Electrochemical tests were conducted in a loop consisting of $1 \mathrm{~h}$ of immersion in an open circuit potential (OCP), and then electrochemical impedance spectroscopy (EIS) was registered. Next, samples were immersed in OCP for $5 \mathrm{~h}$, and EIS was measured once again. The last step of the loop was to obtain potentiodynamic polarization (PDP) curves with a scan rate of $1 \mathrm{mV} / \mathrm{s}$. The EIS tests were performed in a frequency range from $2.5 \times 10^{-2}$ to $5 \times 10^{4} \mathrm{~Hz}$ with a sinusoidal signal amplitude of $10 \mathrm{mV}$. After electrochemical tests, the samples were observed using scanning electron microscopy (SEM) Tescan Vega in backscattered mode (BSE). To identify the phase composition of corrosion products formed during electrochemical measurements and XRD measurements were done.

\section{Results}

\subsection{Microstructure Characterization}

The actual concentration of $\mathrm{Li}$ in the case of the extruded $\mathrm{Mg}-3 \mathrm{Al}-1 \mathrm{Zn}-15 \mathrm{Li}$ is found to be $14.0 \mathrm{wt} . \%$, while the amount of $\mathrm{Li}$ after annealing decreases to $11.9 \mathrm{wt} \%$ (Table 1). The decreased amount of $\mathrm{Li}$ after annealing indicates that during heat treatment the Li evaporation or/and oxidation occurred.

As shown in Fig. 1, the microstructure in both conditions of studied alloy consists of coarse grains with nearly regular size and distribution. When comparing Fig. 1(a) and (b), the microstructure with smaller grain size is obtained for the annealed Mg-3Al-1Zn-15Li. The determined by of the method of linear interception length mean grain size for the extruded microstructure is about $75 \mu \mathrm{m}$ while for the annealed it is found to be about $40 \mu \mathrm{m}$. The optical images indicate that the heat treatment did not lead to the full microstructure homogenization. The XRD patterns show that both alloys are mainly composed of $\beta(\mathrm{Li})$ and $\alpha(\mathrm{Mg})$, and the presence of the second phases $\mathrm{Mg}_{17} \mathrm{Al}_{12}$ and $\mathrm{MgLi}_{2} \mathrm{Al}$ is also confirmed (Fig. 2). Although the presented phase composition is very similar, the semi-quantitative composition given in Table 2 is specific for the alloy before, and after annealing. In the extruded alloy, the
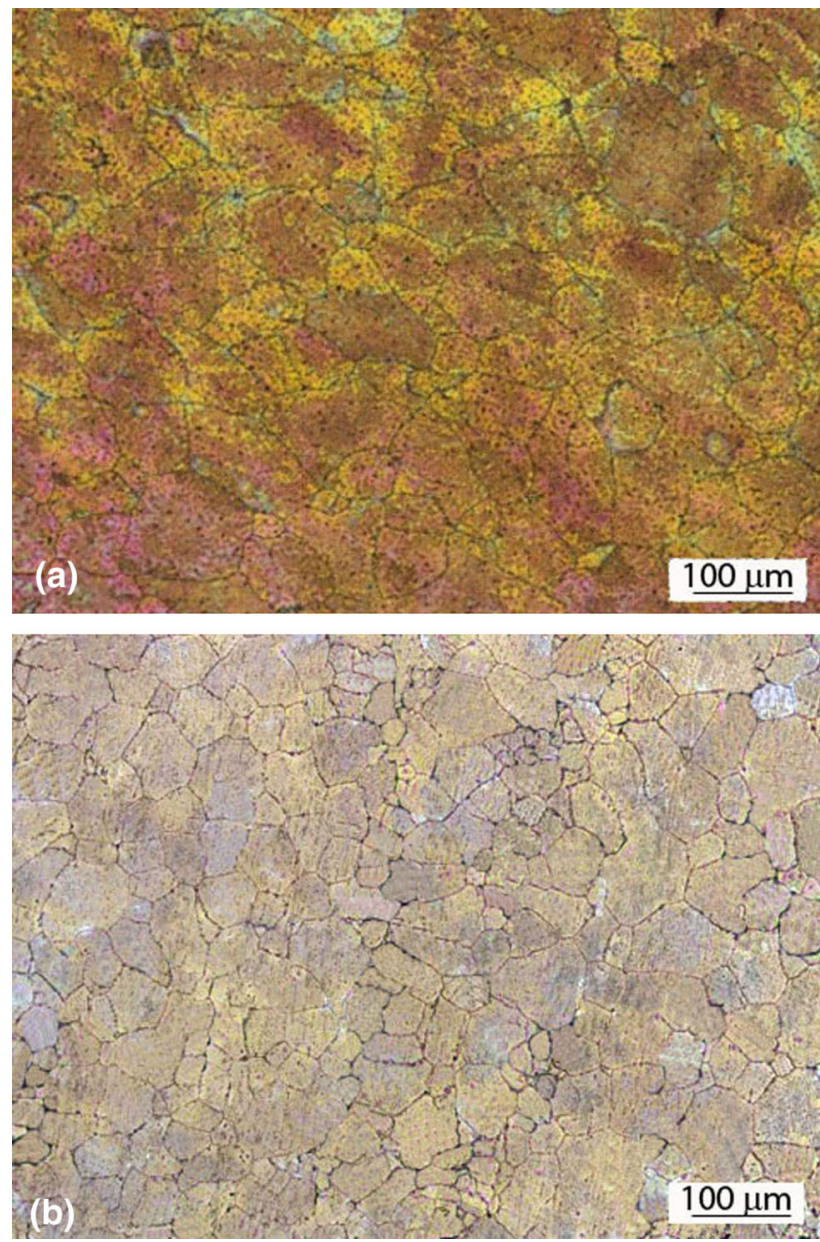

Fig. 1 The optical images of (a) the extruded Mg-3Al-1Zn-15Li, (b) the extruded with subsequent heat treatment Mg-3Al-1Zn-15Li

Table 1 The Li concentration calculated for as-extruded and as-annealed Mg-3Al-1Zn-15Li (wt.\%) 
$\beta(\mathrm{Li})$ phase is predominant over the $\alpha(\mathrm{Mg})$ and the ratio of $\beta(\mathrm{Li})$ to $\alpha(\mathrm{Mg})$ is estimated to be $89-1 \%$. During subsequent heat treatment the $\beta(\mathrm{Li})$ to $\alpha(\mathrm{Mg})$ transformation occurred. Therefore, the ratio of $\beta(\mathrm{Li})$ to $\alpha(\mathrm{Mg})$ in the annealed alloy decreased, and it is found to be $58-31 \%$. According to DSC measurement, the $\beta(\mathrm{Li})$ to $\alpha(\mathrm{Mg})$ transformation could happen when the endothermic reaction was observed reaching its highest intensity at $260{ }^{\circ} \mathrm{C}$ (Fig. 2). The high value of $\Delta H \sim 16 \mathrm{~J} / \mathrm{g}$ suggests that the transformation was very intense, which is consistent with previous results of the numerical simulations obtained by Taylor et al. (Ref 31 ). It is worth to notice that during annealing the $\mathrm{Mg}_{17} \mathrm{Al}_{12}$ precipitated from the matrix, and its relative amount increased from 5 to $7 \%$, while the amount of $\Theta-\mathrm{MgLi}_{2} \mathrm{Al}$ has not been changed (Fig. 3).

\subsection{Electrochemical Testing}

The evolution of $E_{\mathrm{OCP}}$ registered for both materials is presented in Fig. 4. The steady increasing trend of $E_{\mathrm{OCP}}$ for both samples is observed during first hour of measurement. After $1 \mathrm{~h}$ of immersion the $E_{\mathrm{OCP}}$ spike is observed, which is associated with following EIS measurements. After that, the

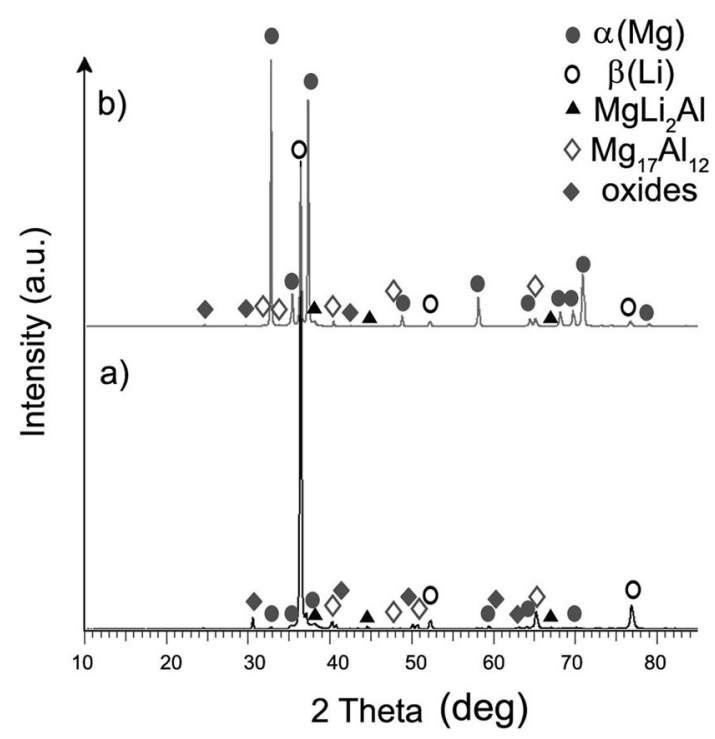

Fig. 2 XRD patterns: (a) the extruded $\mathrm{Mg}-3 \mathrm{Al}-1 \mathrm{Zn}-15 \mathrm{Li}$ and (b) extruded with subsequent heat treatment $\mathrm{Mg}-3 \mathrm{Al}-1 \mathrm{Zn}-15 \mathrm{Li}$

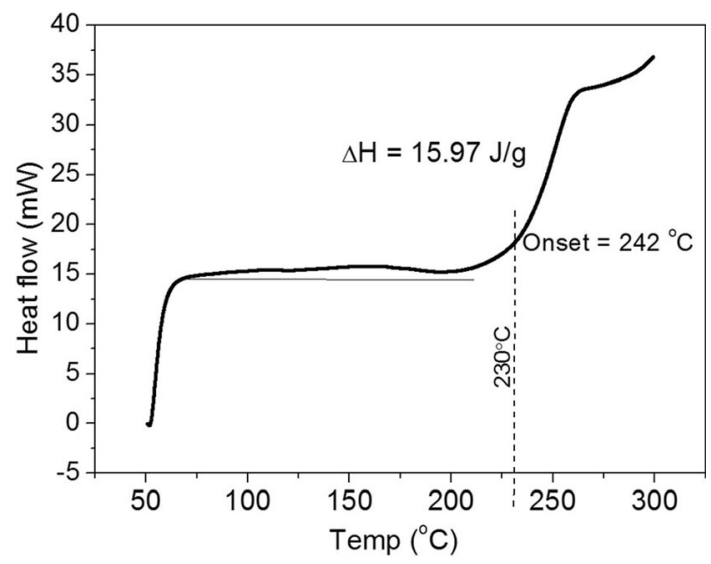

Fig. 3 The DSC curve obtained for the extruded Mg-3Al-1Zn-15Li steady trend in $E_{\mathrm{OCP}}$ evaluation is registered during the all measurement duration, but the values of $E_{\mathrm{OCP}}$ for the extruded Mg-3Al-1Zn-15Li are slightly lower than for the annealed alloy.

The impedance data recorded in $3.5 \mathrm{wt} . \% \mathrm{NaCl}$ solution at OCP after 1 and $6 \mathrm{~h}$ were plotted as Nyquist and Bode plots which are shown in Fig. 5(a), (b), and (c). The shape of all Nyquist plots is similar: a capacitive loop at high and medium frequencies and an inductive loop at low frequencies (Fig. 5a). The experimental results were fitted with an equivalent electric circuit (EEC) shown in Fig. 6. The existence of the capacitive loop in high and medium frequency is related to charge transfer processes (Ref 32) and the resistance of the corrosion products' film (Ref 33). This loop is described by $R_{\mathrm{ct}}$ and $\mathrm{CPE}_{\mathrm{ct}}$, where $R_{\mathrm{ct}}$ is a charge transfer resistance, and $\mathrm{CPE}_{\mathrm{ct}}$ is an electric double-layer capacity at the interface between substrate and electrolyte (Ref 34$)$. $R_{\mathrm{f}}$ represents the porous film resistance and $\mathrm{CPE}_{\mathrm{f}}$ demonstrates the formed oxide film capacity. The second loop which occurred in low frequencies reflects the processes of adsorption of corrosion products on the surface of corroding sample. This loop is described by $R_{\mathrm{L}}$ and $\mathrm{L}$, which are identified with nonhomogeneous adsorption processes.

The recorded values of impedance are very low and typical for active materials that easily corrode in the tested environment (Ref 35, 36). After 1 and $6 \mathrm{~h}$ of the immersion, the diameter of the capacitive loop recorded for the extruded sample is shorter than for the annealed. The more compact corrosion products' layer is formed on the surface of annealed

Table 2 The relative composition of the Mg-3Al-1Zn$15 \mathrm{Li}(\%)$

Relative composition of Mg-3Al-1Zn-15Li, $\%$

\begin{tabular}{lcc} 
Component (phase) & As-extruded & $\begin{array}{c}\text { As-extruded with subsequent } \\
\text { heat treatment }\end{array}$ \\
\hline$\alpha(\mathrm{Mg})$ & 1 & 31 \\
$\beta(\mathrm{Li})$ & 89 & 58 \\
$\mathrm{MgLi}_{2} \mathrm{Al}$ & 1 & 1 \\
$\mathrm{Mg}_{17} \mathrm{Al}_{12}$ & 5 & 7 \\
Oxides & 4 & 3 \\
\hline
\end{tabular}

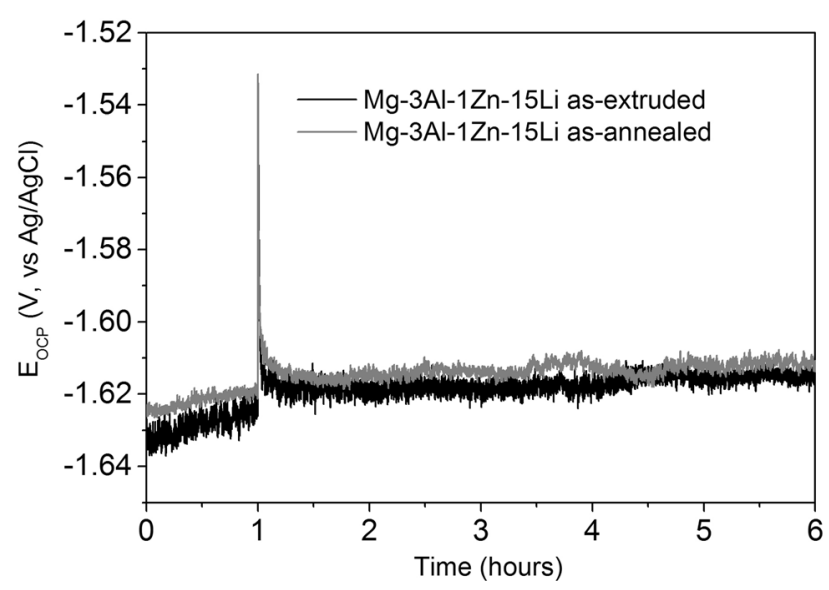

Fig. 4 The $E_{\mathrm{OCP}}$ over1 and next $5 \mathrm{~h}$ of immersion 
sample, which is confirmed by a higher value of $R_{\mathrm{f}}$ obtained after 1 and $6 \mathrm{~h}$ of immersion (after $1 \mathrm{~h}: 440.0$ and $660.0 \Omega \mathrm{cm}^{2}$ and after $6 \mathrm{~h}$ : 199.8 and $329.6 \Omega \mathrm{cm}^{2}$ for the extruded, and extruded with subsequent heat treatment Mg-3Al-1Zn-15Li,
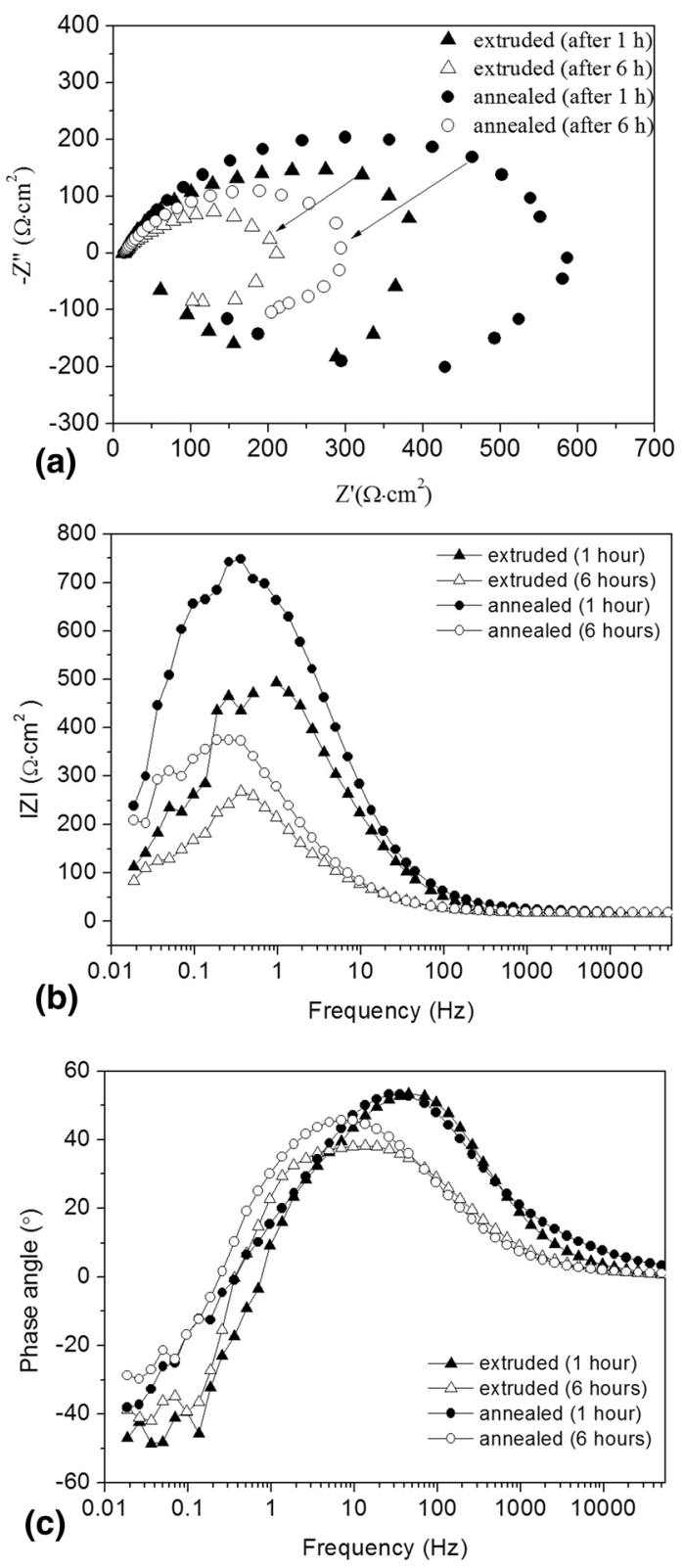

Fig. 5 EIS patterns obtained for the extruded, and the extruded with subsequent heat treatment $\mathrm{Mg}-3 \mathrm{Al}-1 \mathrm{Zn}-15 \mathrm{Li}$ alloys after 1 and $6 \mathrm{~h}$ of immersion in $3.5 \mathrm{wt} . \% \mathrm{NaCl}$ respectively). After $6 \mathrm{~h}$ the $R_{\mathrm{f}}$ value for the extruded, and extruded with subsequent heat treatment samples decreases from 440.0 to 199.8 for the extruded, and from 660.0 to $329.6 \Omega \mathrm{cm}^{2}$ for the annealed sample. The impedance values also decrease after $6 \mathrm{~h}$ of immersion (Fig. 5b). This can be associated with very intensive anodic reactions leading to the material dissolution. As per results presented in Table $2, R_{\mathrm{ct}}$ for the extruded sample decreases from 78.0to $56.8 \Omega \mathrm{cm}^{2}$, and from 78.0 to $55.8 \Omega \mathrm{cm}^{2}$ for the annealed material. The $R_{\mathrm{L}}$ increases with time duration and this is recognized for both analyzed materials. A significant increase is obtained for the sample after extrusion; $R_{\mathrm{L}}$ value increases almost 4 times (from 490.0 to $1800.0 \Omega \mathrm{cm}^{2}$ ). The gain of $\mathrm{R}_{\mathrm{L}}$ is also noted for the annealed material, and its value changes from 600.0 to $876.0 \Omega \mathrm{cm}^{2}$. Nevertheless, as presented in Bode plots of $|Z|$ versus frequency (Fig. 5b), the inductive loop for the alloys after 1 and $6 \mathrm{~h}$ of immersion has started at the same frequency. Following the Langmuir adsorption model (Ref 37, 38), it indicates that the reaction rate constant of the adsorption processes for the both materials is constant, and it suggests that adsorption processes are totally independent of the time of immersion. As presented in Fig. 5(c), the maximum values of the phase angle obtained for both samples after $1 \mathrm{~h}$ of immersion are equal. This indicates that after $1 \mathrm{~h}$ of immersion reaction rate constant of adsorption reaction does not depend on the alloys' microstructures. The values of phase angle registered after $6 \mathrm{~h}$ of immersion are slightly different for the extruded and the annealed material, and it suggests, that the reaction rate constant of adsorption reaction for extruded sample is slightly higher than for annealed one. It may be associated with higher internal energy in the extruded than in the annealed sample (Table 3).

The potentiodynamic polarization curves obtained for analyzed materials after $6 \mathrm{~h}$ of immersion are presented in Fig. 7. The cathodic branch of both polarization curves is driven by hydrogen evaluation reaction and the hydrogen evaluation rate decreases which is confirmed by decreasing current density when moving towards $E_{\text {corr }}$. When the potential reaches the value of $E_{\text {corr, }}$ the current density increases which suggests that up to achieving breakdown potential $\left(E_{\mathrm{b}}\right)$ the

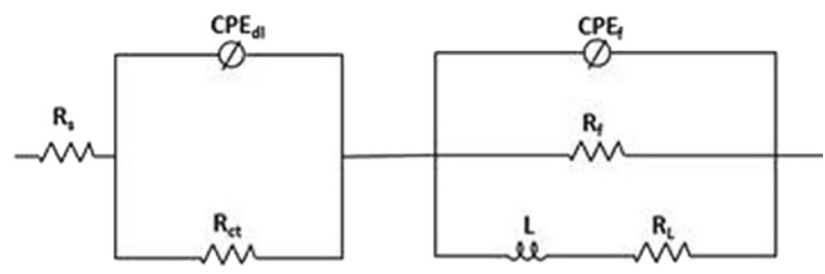

Fig. 6 The equivalent electric circuit (EEC) used for EIS fitting

Table 3 Parameters evaluated from Nyquist plots using equivalent electric circuit fitting

\begin{tabular}{|c|c|c|c|c|c|c|c|c|c|}
\hline Mg-3Al-1Zn-15Li & $R_{\mathrm{s}}, \Omega \mathrm{cm}^{2}$ & $R_{\mathrm{ct}}, \Omega \mathrm{cm}^{2}$ & $\mathrm{CPE}_{\mathrm{dl}}, \mu \mathrm{F} \mathrm{cm}^{-2}$ & $a_{\mathrm{dl}}$ & $R_{\mathrm{f}}, \Omega \mathrm{cm}^{2}$ & $R_{\mathrm{L}}, \Omega \mathrm{cm}^{2}$ & $L, \mathrm{H} \mathrm{cm}^{-2}$ & $\mathrm{CPE}_{\mathrm{f}}, \mu \mathrm{F} \mathrm{cm}^{-2}$ & $a_{\mathrm{f}}$ \\
\hline Extruded $1 \mathrm{~h}$ & 18.0 & 78.0 & 468.0 & 0.81 & 440.0 & 490.0 & 21,876 & 416.0 & 0.81 \\
\hline Extruded $6 \mathrm{~h}$ & 16.9 & 56.8 & 595.0 & 0.75 & 199.8 & 1800.0 & 25,000 & 730.0 & 0.89 \\
\hline Annealed $1 \mathrm{~h}$ & 18.0 & 78.0 & 466.0 & 0.85 & 660.0 & 600.0 & 21,840 & 210.0 & 0.81 \\
\hline Annealed $6 \mathrm{~h}$ & 18.0 & 55.8 & 5213.0 & 0.76 & 329.6 & 876.0 & 17,784 & 814.0 & 0.74 \\
\hline
\end{tabular}


corrosion product film is forming on the investigated materials. The materials started to corrode quickly when $E_{\mathrm{b}}$ is approached. The $E_{\mathrm{b}}$ for Mg-3Al-1Zn-15Li as-extruded occurred at -1.53 $\mathrm{V}_{\mathrm{Ag} / \mathrm{AgCl}}$. When $E_{\mathrm{b}}$ has been achieved, the current density immediately decreased, and after a short while it started to increase. This phenomenon may be related to the second phases dissolution. The $E_{\mathrm{b}}$ for AZ31-15Li after annealing is higher than for the extruded material $\left(-1.48 \mathrm{~V}_{\mathrm{Ag} / \mathrm{AgCl}}\right)$ and no rapid decrease in current density was observed. The obtained for both materials values of $E_{\mathrm{b}}$ are just about $10 \mathrm{mV}$ more positive than $E_{\text {corr }}$, which suggests the formation of the oxide films is very limited in the case of extruded as well the annealed sample. However, the corrosion current density $i_{\text {corr }}$ is two times lower for the annealed sample and is estimated to be 0.04 and $0.02 \mathrm{~mA} \mathrm{~cm}^{-2}$ for AZ31-15Li without and with annealing, respectively (Table 4$)$.

\subsection{Post-corrosion Observations}

Figure 8 and 9 present SEM views for the Mg-3Al-1Zn$15 \mathrm{Li}$ alloys after electrochemical tests. In both cases the surface of analyzed samples after electrochemical tests is well developed (Fig. 8a and 9a). It can be seen that dissolution reactions were not overcompensated by adsorption reactions, as well as reactions leading to the corrosion products formation were very limited, and this is consistent with potentiodynamic results. Images taken with higher magnification indicate that more compact corrosion products were adsorbed on the annealed sample (Fig. $8 \mathrm{~b}$ and $9 \mathrm{~b}$ ). In both cases the corrosion products were mainly composed of $\mathrm{Mg}(\mathrm{OH})_{2}$ and $\mathrm{Al}_{2} \mathrm{O}_{3}$ (Fig. 10). Moreover, $\mathrm{MgAl}_{2} \mathrm{O} \cdot 4 \mathrm{H}_{2} \mathrm{O}$ and $\mathrm{LiMgCl}_{2}$ were also detected.

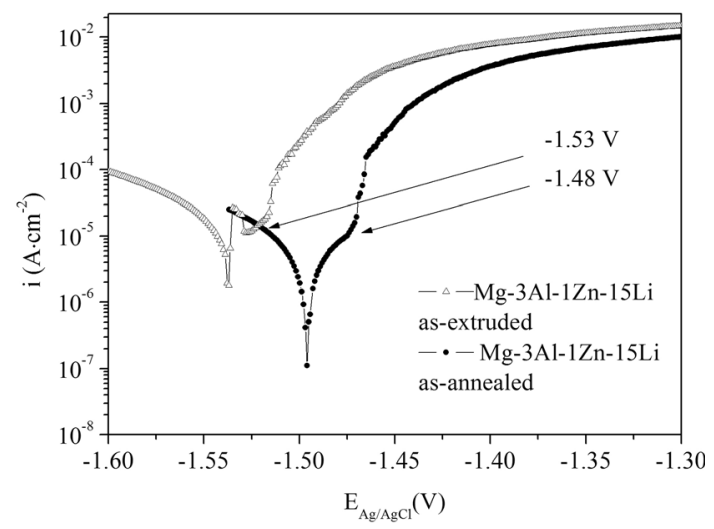

Fig. 7 The potentiodynamic curves of analyzed materials obtained in 3.5 wt. $\% \mathrm{NaCl}$ at ambient temperature

Table 4 Electrochemical parameters calculated from Tafel extrapolation of potentiodynamic polarization curves

\begin{tabular}{|c|c|c|}
\hline Mg-3Al-1Zn-15Li & $\begin{array}{l}E_{\text {corr vs. }} \mathbf{A g} / \\
\quad \mathrm{AgCl}, \mathrm{V}\end{array}$ & $\underset{\text { corr }}{i_{\text {cm }}} \mathbf{m A}^{-2}$ \\
\hline As-extruded & -1.54 & 0.04 \\
\hline $\begin{array}{l}\text { As-extruded with subsequent heat } \\
\text { treatment }\end{array}$ & -1.49 & 0.02 \\
\hline
\end{tabular}

\section{Discussion}

The corrosion resistance of the as-extruded and the asextruded with subsequent heat treatment $\mathrm{Mg}-3 \mathrm{Al}-1 \mathrm{Zn}-15 \mathrm{Li}$ alloys varied due to occurred during subsequent heat treatment phase transformation. Based on XRD patterns, as-extruded and as-extruded with subsequent heat treatment alloys were mainly composed of $\alpha(\mathrm{Mg}), \beta(\mathrm{Li}), \Theta-\mathrm{MgLi}_{2} \mathrm{Al}$ and $\mathrm{Mg}_{17} \mathrm{Al}_{12}$. Due to subsequent at $200{ }^{\circ} \mathrm{C}$ for $1 \mathrm{~h}$ annealing, the $\beta \rightarrow \alpha$ transformation occurred, and precipitation of $\mathrm{Mg}_{17} \mathrm{Al}_{12}$ were observed.

Both alloys, as-extruded and as-extruded with subsequent heat treatment corroded uniformly. The main corrosion mechanism in dual structured $\mathrm{Mg}-\mathrm{Li}$ alloys is a micro-galvanic corrosion between $\alpha(\mathrm{Mg})$ and $\beta(\mathrm{Li})$ which strongly depends on the volume fraction between $\alpha(\mathrm{Mg})$ and $\beta(\mathrm{Li})$. The results presented in this work clearly demonstrates that the increasing amount of $\alpha(\mathrm{Mg})$, which because of its nature possess better corrosion resistance than $\beta(\mathrm{Li})$, was the main reason of improved corrosion resistance of the heat-treated alloy. When exposed to corrosive medium $\alpha(\mathrm{Mg})$ is more stable than $\beta(\mathrm{Li})$,
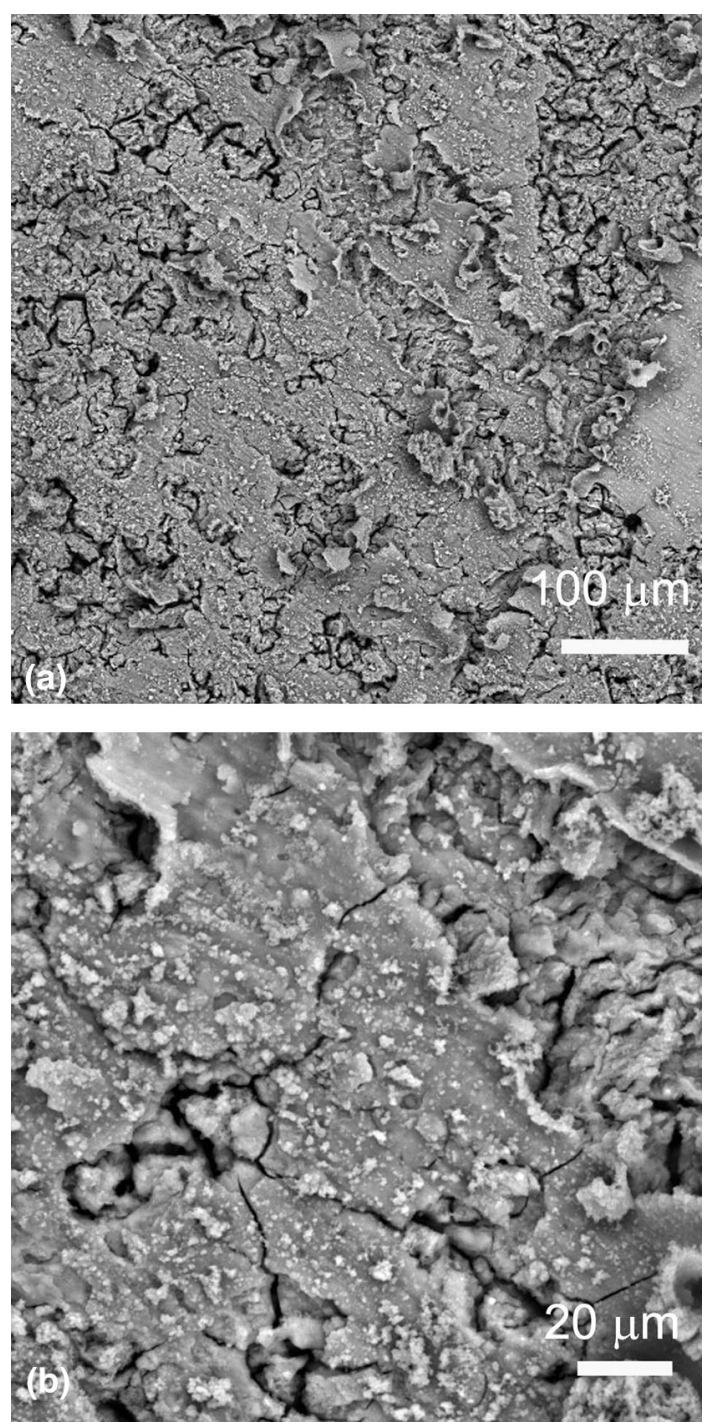

Fig. 8 Post-corrosion observations obtained for the extruded $\mathrm{Mg}$ $3 \mathrm{Al}-1 \mathrm{Zn}-15 \mathrm{Li}$ (a) and (b) surface morphology with different magnification 

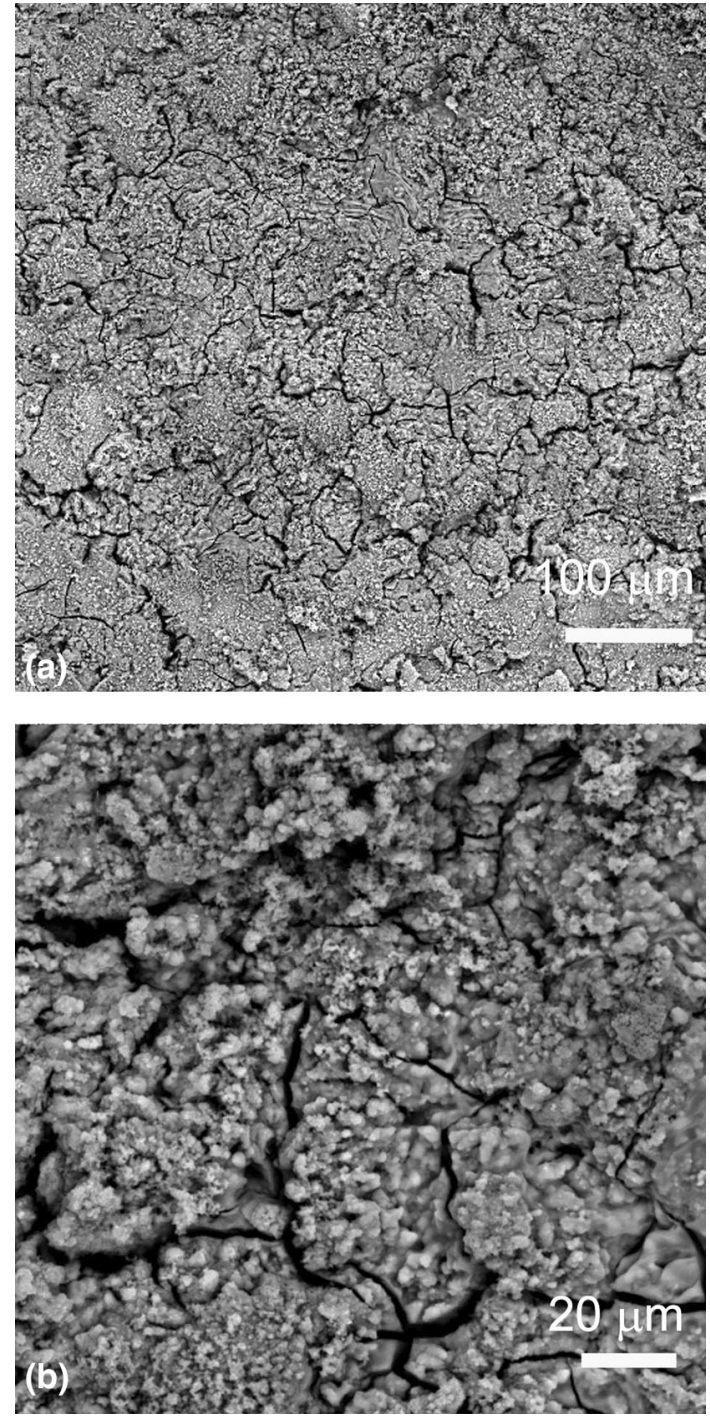

Fig. 9 Post-corrosion observations obtained for the annealed Mg$3 \mathrm{Al}-1 \mathrm{Zn}-15 \mathrm{Li}$ (a) and (b) surface morphology with different magnification

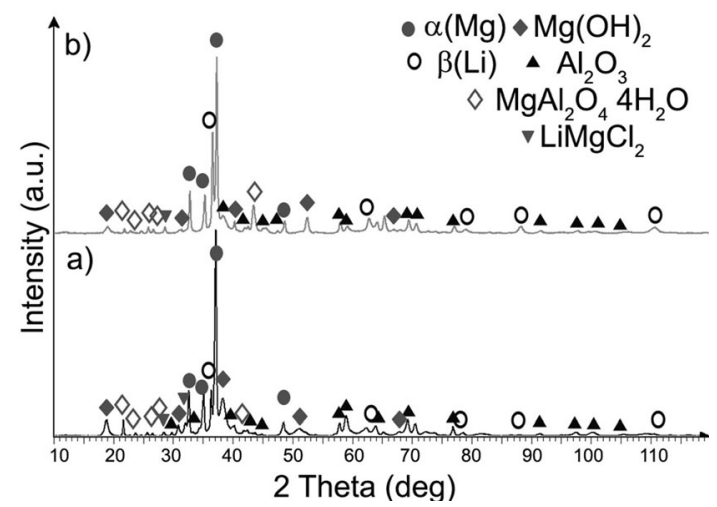

Fig. 10 XRD patterns obtained for samples after electrochemical tests (a) the extruded $\mathrm{Mg}-3 \mathrm{Al}-1 \mathrm{Zn}-15 \mathrm{Li}$, and (b) extruded with subsequent heat treatment $\mathrm{Mg}-3 \mathrm{Al}-1 \mathrm{Zn}-15 \mathrm{Li}$

and it might support formation of slightly denser corrosion products on the surface of the annealed sample. However, the corrosion products were formed very randomly, and they did not create any continuous form of the oxide layer. The identified corrosion products were multicomponent, and these types of films formed on the $\mathrm{Mg}-\mathrm{Li}$ alloys have characteristic porous and loose structure (Ref 26, 39, 40). In this work, the substrate was randomly covered with multicomponent corrosion products, where $\mathrm{Mg}(\mathrm{OH})_{2}$ and $\mathrm{Al}_{2} \mathrm{O}_{3}$ were detected. As it was described for the AZ31 and AZ91 alloys, the reason for the $\mathrm{Al}_{2} \mathrm{O}_{3}$ formation is reactions occurring when local $\mathrm{pH}$ in cathodic reaction increases the solubility of $\mathrm{Al}$. Then in the neutral solutions the $\mathrm{Al}_{2} \mathrm{O}_{3}$ can be formed ( $\mathrm{Ref} 41$ ):

$2 \mathrm{Al}+3 \mathrm{H}_{2} \mathrm{O} \rightarrow \mathrm{Al}_{2} \mathrm{O}_{3}+6 \mathrm{H}+6 \mathrm{e}$

$\mathrm{Al}_{2} \mathrm{O}_{3}$ is generally more stable than $\mathrm{Mg}(\mathrm{OH})_{2}$, and it can be deduced that its higher content in adsorbed corrosive products can favor to obtain more continuous and impact film on the surface of the Mg-Al-Li alloys. Al has a major role in corrosion of $\mathrm{Mg}-\mathrm{Al}$ alloys, and so far the effect of the second phase $\mathrm{Mg}_{17} \mathrm{Al}_{12}$ in the corrosion of $\mathrm{Mg}-\mathrm{Al}$ alloys was widely investigated (Ref 33, 42-45). Depending on its amount and distribution (continues or discontinuous) the presence of $\mathrm{Mg}_{17} \mathrm{Al}_{12}$ can favor or block corrosion reactions (Ref 46,47 ). The presented results show that the adsorption processes were supported by $\mathrm{Al}^{3+}$ ions, which dissolved to the solution from the matrix and second phases. There is a probability that in the case of the analyzed materials the presence of second phase $\mathrm{Mg}_{17} \mathrm{Al}_{12}$ improves passivation ability of the heat-treated alloy, but the passivation is still very limited. Based on the presented experiments, there is no other indication about role of $\mathrm{Mg}_{17} \mathrm{Al}_{12}$ in the corrosion of Mg-Al-Li. However, it is clearly seen that the formation of the corrosion products was additionally blocked. As the corrosion of Mg-Al-Li alloys is a very complicated process, it has to be noted that adsorption reactions can be disturbed by dynamic Li dissolution (Ref 48) and in solutions containing chlorides, the quality of the anodic passive film on the Mg-Al-Li alloys generally decreases due to localized attack of $\mathrm{Cl}^{-}$(Ref 49).

\section{Conclusions}

The phase transformation and corrosion behavior of AZ31$15 \mathrm{Li}$ as-extruded and as-extruded with subsequent heat treatment were presented in this study. The following conclusions can be drawn:

1. As a result of the heat treatment $\left(200{ }^{\circ} \mathrm{C}\right.$ for $\left.1 \mathrm{~h}\right)$ the $\beta \rightarrow \alpha$ transformation occurred in the Mg-3Al-1Zn$15 \mathrm{Li}$.

2. Both alloys: as-extruded and as-extruded with subsequent heat treatment, corroded uniformly. Because of initialization of the $\beta \rightarrow \alpha$ transformation, the increasing amount of $\alpha(\mathrm{Mg})$ influenced in $\mathrm{Mg}-3 \mathrm{Al}-1 \mathrm{Zn}-15 \mathrm{Li}$ corrosion resistance improvement.

3. The presence of higher amount of $\mathrm{Mg}_{17} \mathrm{Al}_{12}$ probably supported passivation ability of the heat-treated Mg-3Al$1 \mathrm{Zn}-15 \mathrm{Li}$.

\section{Acknowledgments}

The authors would like to thank Prof. Dalibor Vojtechand Dr Jirij Kubasek from the Department of Metals and Corrosion 
Engineering of the University of Chemistry and Technology in Prague, Czechia, for their support in corrosion testing.

\section{Open Access}

This article is licensed under a Creative Commons Attribution 4.0 International License, which permits use, sharing, adaptation, distribution and reproduction in any medium or format, as long as you give appropriate credit to the original author(s) and the source, provide a link to the Creative Commons licence, and indicate if changes were made. The images or other third party material in this article are included in the article's Creative Commons licence, unless indicated otherwise in a credit line to the material. If material is not included in the article's Creative Commons licence and your intended use is not permitted by statutory regulation or exceeds the permitted use, you will need to obtain permission directly from the copyright holder. To view a copy of this licence, visit http://creativecommons.org/licenses/by/4.0/.

\section{References}

1. Z. Yang, J.P. Li, J.X. Zhang, G.W. Lorimer, and J. Robson, Review on Research and Development of Magnesium Alloys, Acta Metall. Sin., 2008, 21(5), p 313-328. https://doi.org/10.1016/S1006-7191(08)6005 4-X

2. P. Metenier, G. González-Doncel, O.A. Ruano, J. Wolfenstine, and O.D. Sherby, Superplastic Behavior of a Fine-Grained Two-Phase Mg9wt.\%Li Alloy, Mater. Sci. Eng. A, 1990, 125(2), p 195-202. https://d oi.org/10.1016/0921-5093(90)90169-4

3. G. Wei, Y. Mahmoodkhani, X. Peng, A. Hadadzadeh, T. Xu, J. Liu, W. Xie, and M.A. Wells, Microstructure Evolution and Simulation Study of a Duplex Mg-Li Alloy during Double Change Channel Angular Pressing, Mater. Des., 2016, 90, p 266-275. https://doi.org/10.1016/j. matdes.2015.10.143

4. W. Xu, N. Birbilis, G. Sha, Y. Wang, J.E. Daniels, Y. Xiao, and M. Ferry, A High-Specific-Strength and Corrosion-Resistant Magnesium Alloy, Nat. Mater, 2015, 14(12), p 1229-1235. https://doi.org/10.103 8/nmat4435

5. M.A. Gharghouri, G.C. Weatherly, and J.D. Embury, The Interaction of Twins and Precipitates in a Mg-7.7 at.\% Al Alloy, Philos. Mag. A Phys. Condens. Matter, Struct. Defects Mech. Prop., 1998, 78(5), p $1137-$ 1149. https://doi.org/10.1080/01418619808239980

6. B. Kondori and A.A. Benzerga, On the Notch Ductility of a Magnesium-Rare Earth Alloy, Mater. Sci. Eng. A, 2015, 647, p 74 83. https://doi.org/10.1016/j.msea.2015.08.077

7. J.J. Bhattacharyya, F. Wang, P.D. Wu, W.R. Whittington, H. El Kadiri, and S.R. Agnew, Demonstration of Alloying, Thermal Activation, and Latent Hardening Effects on Quasi-Static and Dynamic Polycrystal Plasticity of Mg Alloy, WE43-T5, Plate, Int. J. Plast., 2016, 81, p 123151. https://doi.org/10.1016/j.ijplas.2016.01.005

8. J. Wang, Q. Zhang, and J. Qin, Structural Transition Region of Liquid Mg-Li Alloys, Comput. Mater. Sci., 2016, 117, p 259-265. https://doi. org/10.1016/j.commatsci.2016.01.035

9. L.A. Simons, J. Simons, J. McCallum, and Y. Friedlander, The Activity of Non-Basal Slip Systems and Dynamic Recovery at Room Temperature in Fine-Grained AZ31B Magnesium Alloys, Acta Mater, 2003, 51, p 2055-2065. https://doi.org/10.1016/S1359-6454(03)00005-3

10. J. Koike, Enhanced Deformation Mechanisms by Anisotropic Plasticity in Polycrystalline Mg Alloys at Room Temperature, Metall. Mater. Trans. A Phys. Metall. Mater. Sci., 2005, 36(7), p 1689-1696. https://d oi.org/10.1007/s11661-005-0032-4

11. H. Haferkamp, R. Boehm, U. Holzkamp, C. Jaschik, V. Kaese, and M. Niemeyer, Alloy Development, Processing and Applications in Magnesium Lithium Alloys, Mater. Trans., 2001, 42(7), p 1160-1166. h ttps://doi.org/10.4028/www.scientific.net/MSF.350-351.31

12. W.A. Counts, M. Friák, D. Raabe, and J. Neugebauer, Using Ab Initio Calculations in Designing Bcc MgLi-X Alloys for Ultra-Lightweight Applications, Adv. Eng. Mater., 2010, 12(12), p 1198-1205. https://doi. org/10.1002/adem.201000225
13. M. Tsujikawa, Y. Abe, S.W. Chung, S. Oki, K. Higashi, I. Hiraki, and M. Kamita, Cold-Rolled Mg-14 Mass\%Li-1 Mass\%Al Alloy and Its Friction Stir Welding, Mater. Trans., 2006, 47(4), p 1077-1081. h ttps://doi.org/10.2320/matertrans.47.1077

14. A. Białobrzeski, M. Lech-grega, and J. Zelechowski, Scanning Examinations of Magnesium- and Lithium- Based Alloys of TwoPhase $\alpha-\beta$ and Monophase $\beta$ Structure, Pr. Inst. Odlew., 2010, 1(L), p 17-28. https://doi.org/10.7356/iod.2010.2

15. G.H. Park, J.T. Kim, H.J. Park, Y.S. Kim, H.J. Jeong, N. Lee, Y. Seob, J.-Y. Suh, H.-T. Son, W.-M. Wang, J.M. Park, and K.B. Kim, Development of Lightweight Mg-Li-Al Alloys with High Specific Strength, J. Alloys Compd., 2016, 680, p 116-120. https://doi.org/10. 1016/j.jallcom.2016.04.109

16. R.Z. Wu, Z.K. Qu, and M. Zhang, Reviews on the Influences of Alloying Elements on the Microstructure and Mechanical Properties of Aluminum Alloys and Aluminum Alloy Composites, Rev. Adv. Mater. Sci., 2010, 24, p 35-43

17. R. Wu, Y. Yan, G. Wang, L.E. Murr, W. Han, Z. Zhang, and M. Zhang, Recent Progress in Magnesium-Lithium Alloys, Int. Mater. Rev., 2015, 60(2), p 65-100. https://doi.org/10.1179/1743280414Y.0000000044

18. X. Meng, R. Wu, M. Zhang, L. Wu, and C. Cui, Microstructures and Properties of Superlight Mg-Li-Al-Zn Wrought Alloys, J. Alloys Compd., 2009, 486(1-2), p 722-725. https://doi.org/10.1016/j.jallcom. 2009.07.047

19. I.F. Mohamed, Y. Yonenaga, S. Lee, K. Edalati, and Z. Horita, Age Hardening and Thermal Stability of Al-Cu Alloy Processed by HighPressure Torsion, Mater. Sci. Eng. A, 2015, 627, p 111-118. https://doi. org/10.1016/j.msea.2014.12.117

20. J.S. Leu, C. Te Chiang, S. Lee, Y.H. Chen, and C.L. Chu, Strengthening and Room Temperature Age-Softening of Super-Light Mg-Li Alloys, J. Mater. Eng. Perform., 2010, 19(9), p 1235-1239. h ttps://doi.org/10.1007/s11665-010-9606-4

21. P. Fei, Z. Qu, and R. Wu, Microstructure and Hardness of Mg-9Li-6AlXLa $(X=0,2,5)$ Alloys during Solid Solution Treatment, Mater. Sci. Eng. A, 2015, 625, p 169-176. https://doi.org/10.1016/j.msea.2014.12. 014

22. Y. Tang, W. Jia, X. Liu, Q. Le, and Y. Zhang, Fabrication of High Strength $\alpha, \alpha+\beta, \beta$ Phase Containing Mg-Li Alloys with $0.2 \% \mathrm{Y}$ by Extruding and Annealing Process, Mater. Sci. Eng. A, 2016, 675, p 55-64. https://doi.org/10.1016/j.msea.2016.08.007

23. X. Guo, R. Wu, J. Zhang, B. Liu, and M. Zhang, Influences of Solid Solution Parameters on the Microstrucuture and Hardness of Mg-9Li6Al and Mg-9Li-6Al-2Y, Mater. Des., 2014, 53, p 528-533. https://doi. org/10.1016/j.matdes.2013.07.011

24. Z. Qu, R. Wu, H. Zhan, and M. Zhang, The Solution and Room Temperature Aging Behavior of $\operatorname{Mg}-9 \mathrm{Li}-\mathrm{XAl}(x=3,6)$ Alloys, J. Alloys Compd., 2012, 536, p 145-149. https://doi.org/10.1016/j.jallcom.2012. 05.021

25. T. Liu, S.D. Wu, S.X. Li, and P.J. Li, Microstructure Evolution of Mg-14\% Li-1\% Al Alloy During the Process of Equal Channel Angular Pressing, Mater. Sci. Eng. A, 2007, 460-461, p 499-503. h ttps://doi.org/10.1016/j.msea.2007.01.108

26. L. Gao, C. Zhang, M. Zhang, X. Huang, and N. Sheng, The Corrosion of a Novel Mg-11Li-3Al-0.5RE Alloy in Alkaline NaCl Solution, $J$. Alloys Compd., 2009, 468(1-2), p 285-289. https://doi.org/10.1016/j.ja 1lcom.2007.12.080

27. W. Miao, C. Che, K. Fu, R. Wu, L. Hou, J. Zhang, and M. Zhang, Microstructure and Mechanical Properties of $\operatorname{Mg}-8 \mathrm{Li}-(0,1,2) \mathrm{Ca}-(0$, 2)Gd Alloys, J. Mater. Eng. Perform., 2017, 26(10), p 4831-4837

28. V. Kumar, R. Shekhar, and K. Balani, Corrosion Behavior of Novel Mg-9Li-7Al-1Sn and Mg-9Li-5Al-3Sn-1Zn Alloys in $\mathrm{NaCl}$ Aqueous Solution, J. Mater. Eng. Perform., 2015, 24(10), p 4060-4070

29. D. Kuc, E. Hadasik, I. Schindler, P. Kawulok, and R. Śliwa, Characteristics of Plasticity and Microstructure of Hot Forming Magnesium Alloys Mg-Al-Zn Type, Arch. Metall. Mater, 2013, 58(1), p 151-156

30. J. Dutkiewicz, S. Rusz, D. Kuc, O. Hilser, P. Bobrowski, and B. Kania, Microstructure and Texture Changes of MgLiAl Alloys Composed of $\alpha$ or $\alpha+\beta$ Phases after Twist Channel Angular Pressing TCAP, Arch. Metall. Mater., 2018, 63, p 1827-1835

31. R.H. Taylor, S. Curtarolo, and G.L.W. Hart, Ordered MagnesiumLithium Alloys: First-Principles Predictions, Phys. Rev. B, 2010, 81(024112), p 1-8 
32. G. Ben Hamu, D. Eliezer, and L. Wagner, The Relation between Severe Plastic Deformation Microstructure and Corrosion Behavior of AZ31 Magnesium Alloy, J. Alloys Compd., 2009, 468, p 222-229

33. I.B. Singh, M. Singh, and S. Das, A Comparative Corrosion Behavior of $\mathrm{Mg}, \mathrm{AZ31}$ and AZ91 Alloys in 3.5\% NaCl Solution, J. Magnes. Alloys, 2015, https://doi.org/10.1016/j.jma.2015.02.004

34. C.Q. Li, D.K. Xu, X.B. Chen, B.J. Wang, R.Z. Wu, E.H. Han, and N. Birbilis, Composition and Microstructure Dependent Corrosion Behaviour of Mg-Li Alloys, Electrochim. Acta, 2018, 260, p 55-64

35. Y.L. Cheng, T.W. Qin, H.M. Wang, and Z. Zhang, Comparison of Corrosion Behaviors of AZ31, AZ91, AM60 and ZK60 Magnesium Alloys, Trans. Nonferrous Met. Soc. China (English Ed.)), 2009, 19(3), p 517-524. https://doi.org/10.1016/s1003-6326(08)60305-2

36. Y. Song, D. Shan, R. Chen, and E.H. Han, Investigation of Surface Oxide Film on Magnesium Lithium Alloy, J. Alloys Compd., 2009, 484(1-2), p 585-590

37. G. Galicia, N. Pébère, B. Tribollet, and V. Vivier, Local and Global Electrochemical Impedances Applied to the Corrosion Behaviour of an AZ91 Magnesium Alloy, Corros. Sci., 2009, 51(8), p 1789-1794. h ttps://doi.org/10.1016/j.corsci.2009.05.005

38. S. Thirugnanaselvi, S. Kuttirani, and A.R. Emelda, Effect of Schiff Base as Corrosion Inhibitor on AZ31 Magnesium Alloy in Hydrochloric Acid Solution, Trans. Nonferrous Met. Soc. China., 2014, 24(6), p 1969-1977. https://doi.org/10.1016/s1003-6326(14)63278-7

39. G. Liu, W. Xie, G. Wei, Y. Yang, J. Liu, T. Xu, W. Xie, and X. Peng, Dynamic Recrystallization Behavior and Corrosion Resistance of a Dual-Phase Mg-Li Alloy, Materials (Basel), 2018, 11(3), p 1-11. h ttps://doi.org/10.3390/ma11030408

40. R.-C. Zeng, L. Sun, Y.-F. Zheng, H.-Z. Cui, and E.-H. Han, Corrosion and Characterisation of Dual Phase Mg-Li-Ca Alloy in Hank's Solution: The Influence of Microstructural Features, Corros. Sci., 2014, 79, p 69-82. https://doi.org/10.1016/j.corsci.2013.10.028

41. L. Wang, T. Shinohara, and B.P. Zhang, XPS Study of the Surface Chemistry on AZ31 and AZ91 Magnesium Alloys in Dilute $\mathrm{NaCl}$ Solution, Appl. Surf. Sci., 2010, https://doi.org/10.1016/j.apsusc.2010. 02.058
42. R. Ambat, N.N. Aung, and W. Zhou, Evaluation of Microstructural Effects on Corrosion Behaviour of AZ91D Magnesium Alloy, Corros. Sci., 2000, 42, p 1433-1455

43. F. Witte, N. Hort, C. Vogt, S. Cohen, K.U. Kainer, R. Willumeit, and F. Feyerabend, Degradable Biomaterials Based on Magnesium Corrosion, Curr. Opin. Solid State Mater. Sci., 2008, 12(5-6), p 63-72. https://doi. org/10.1016/j.cossms.2009.04.001

44. T. Morishige, Y. Obata, T. Goto, T. Fukagawa, E. Nakamura, and T. Takenaka, Effect of Al Composition on the Corrosion Resistance of Mg-14 Mass\% Li System Alloy, Mater. Trans., 2016, 57(10), p 18531856. https://doi.org/10.2320/matertrans.M2016247

45. P. Bhagat Singh, R.K. Sabat, S. Kumaran, and S. Suwas, Effect of Aluminum Addition on the Evolution of Microstructure, Crystallographic Texture and Mechanical Properties of Single Phase Hexagonal Close Packed Mg-Li Alloys, J. Mater. Eng. Perform., 2015, 27(2), p 864-874. https://doi.org/10.1007/s11665-018-3164-6

46. S. Feliu and I. Llorente, Corrosion Product Layers on Magnesium Alloys AZ31 and AZ61: Surface Chemistry and Protective Ability, Appl. Surf. Sci., 2015, 347, p 736-746. https://doi.org/10.1016/j.apsu sc.2015.04.189

47. O. Lunder, J.E. Lein, T.K. Aune, and K. Nisancioglu, Role of $\mathrm{Mg}_{17} \mathrm{Al}_{12}$ Phase in the Corrosion of Mg Alloy AZ91, Corrosion, 1989, 45(9), p 741-748. https://doi.org/10.5006/1.3585029

48. L. Hou, M. Raveggi, X.-B. Chen, W. Xu, K.J. Laws, Y. Wei, M. Ferry, and N. Birbilis, Investigating the Passivity and Dissolution of a Corrosion Resistant Mg-33at\%Li Alloy in Aqueous Chloride Using Online ICP-MS, J. Electrochem. Soc., 2016, 163(6), p C324-C329. h ttps://doi.org/10.1149/2.0871606jes

49. D.K. Xu and E.H. Han, Effect of Quasicrystalline Phase on Improving the Corrosion Resistance of a Duplex Structured Mg-Li Alloy, Scr. Mater., 2014, 71, p 21-24. https://doi.org/10.1016/j.scriptamat.2013. 09.025

Publisher's Note Springer Nature remains neutral with regard to jurisdictional claims in published maps and institutional affiliations. 